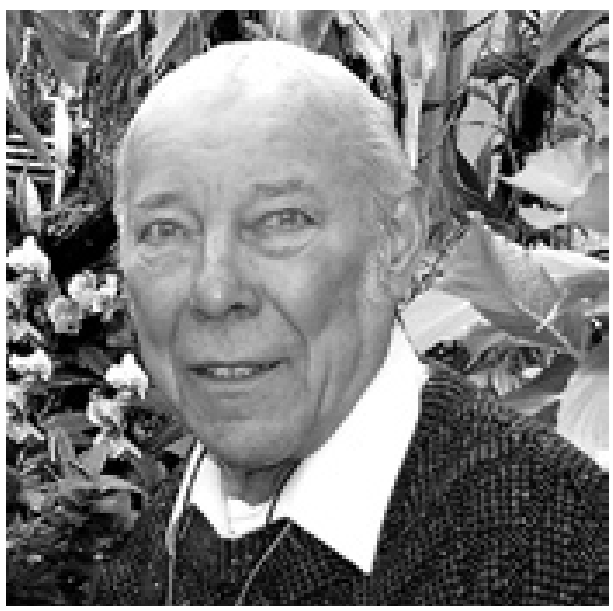

Karlheinz Senghas (1928-2004). Cortesía de la Sociedad Alemana de Orquideología (D.O.G.).

\title{
MEMORIA DE UNO DE LOS GRANDES DE LA ORQUIDEOLOGÍA MUNDIAL: KARLHEINZ SENGHAS (1928-2004)
}

\author{
Carlos O. Morales \\ Jardín Botánico Lankester y Escuela de Biología, Universidad de Costa Rica, 2060, San José, Costa Rica.
}

El 4 de febrero de 2004 murió este científico alemán de renombre mundial, quien dejó profundas huellas, tanto en el ámbito de los botánicos como de los orquideófilos. Conocí la noticia de su muerte en un número de la revista Die Orchidee (Anónimo 2004), que recibí varios meses después de su publicación.

Tal como relatan Senger \& Senger (2004), Senghas nació el 7 de abril de 1928 en la ciudad de Stuttgart, donde cursó la escuela primaria. En 1939, la familia se mudó a Mannheim porque el padre era soldado y fue trasladado allí. En 1994 y 1995 yo viví en Mannheim y supe que el $80 \%$ de esta ciudad industrial, en la región sudoccidental de Alemania, fue destruido por bombardeos aéreos en la Segunda Guerra Mundial. Así, en esos crudos años de guerra la vida del joven Senghas debió ser muy difícil. Con apenas 17 años, tuvo que abandonar la secundaria y marchar hacia Francia, donde colaboró con las fuerzas armadas en la defensa antiaérea. En Mannheim, a inicios de 1945 un bombardeo aéreo alcanzó la casa de la familia, causando la muerte de la hermana y la pérdida de un brazo de la madre. Prisionero de guerra por breve tiempo (hasta otoño de 1945), después de la guerra volvió a la secundaria y entre 1949 y 1954 estudió biología en la Universidad de Heidelberg, sin duda una de las más prestigiosas de Alemania. Obtuvo su Diplom y su Promotion (doctorado, 1959) dirigido por el prestigioso Prof. Dr. Werner Rauh (1914-2000, a quien recordamos en nombres de especies y de los géneros Rauhia, Rauhiella, Rauhocereus y Werauhia), quien le ofreció un puesto en el Instituto de Botánica de Heidelberg. Allí fue coautor de Rauh en la sexagésima cuarta $\left(64^{\mathrm{a}}\right.$.) edición de la Flora von Deutschland (Flora de Alemania) de Schmeil-Fitschen, una obra de consulta obligada para todo botánico interesado en la flora de Europa central. Numerosas ediciones nuevas de esta Flora aparecieron en años posteriores, hasta llegar a la nonagésima primera $\left(91^{\mathrm{a}}\right.$.) en 2003, por K. Senghas y Siegmund Seibold. Una tradición y un perfeccionismo cultivados con esmero, como ocurre rara vez en otras latitudes.

En 1956 se casó con Irmgard Senghas; con ella formó una familia y engendró tres hijos. En 1960 fue nombrado curador y director científico del Jardín Botánico de Heidelberg. Ya en aquel entonces, Rauh lo convenció de ocuparse de la colección de orquídeas, con el argumento de que una sola persona no puede organizar y mejorar varias colecciones al mismo 
tiempo. En 1980, Senghas fue nombrado Director Académico del Jardín Botánico de Heidelberg. Viajó a diversos países y diversas regiones del mundo y visitó numerosos jardines botánicos y herbarios. Desde 1962, produjo más de 300 publicaciones sobre orquídeas; de éstas, describió 17 géneros; también subgéneros, secciones y muchas especies. Recolectó numerosas plantas y especímenes y mantuvo un activo intercambio a nivel mundial, tanto así que al asumir funciones en 1960, el Jardín Botánico poseía ca. 400 especies en cultivo, al pensionarse en 1993 eran cerca de 6000 especies. Al mismo tiempo, se mantenía muy activo en el ámbito de los gremios aficionados a las orquídeas, agrupados en la Sociedad Alemana de Orquideología (D.O.G.), e incluso editó memorias de importantes encuentros de orquideófilos. Durante $c a$. 25 años dirigió el grupo del Palatinado y entre 1976 y 1978 fue presidente de la D.O.G.

Llegó a acumular un gran conocimiento sobre las orquídeas y siempre estaba dispuesto a compartirlo con los interesados. Como revelan quienes lo conocieron (v.g. Senger \& Senger 2002, 2004), al estudiar orquídeas, su mayor propósito era investigar y analizar toda clase de material vivo disponible. Las siguientes fuentes de información eran el Jardín Botánico de Heidelberg y las colecciones de los aficionados.

Desde 1970 fue coeditor (el más joven), después editor (el último) y coautor de la tercera edición del manual fundado por Rudolf Schlechter Die Orchideen, una obra de tres volúmenes que, con suplementos, índice de literatura, índice general e índices de los volúmenes I/A, B y C, abarca unas 4000 páginas y pudo terminarse hasta el año 2002 (vide Lankesteriana 6: 29-31. 2003). Fue la gran obra de su vida; otra como ésta no se escribirá nunca más. Como lo expresa Haber (1998), solamente una persona con la perseverancia, la tenacidad y la obsesión de Senghas pudo haber terminado una obra de tal magnitud, después de 32 años de haberla iniciado.

Dos géneros orquidáceos le fueron dedicados: Senghasiella Szlach. [J. Orchideenfr. 8(4): 365.
2001, segregado de Habenaria Willd.] y Senghasia Szlach. [J. Orchideenfr. 10(4): 335. 2003, segregado de Kefersteinia Rchb.f., sectio Umbonatae]. Además, los nombres de las especies Masdevallia senghasiana Luer (de Colombia) y Coryanthes senghasiana G.Gerlach (de Perú) nos harán siempre recordar a este eminente botánico, cuyas ideas no siempre fueron aceptadas por sus colegas. No obstante, es bueno saber que la taxonomía botánica siempre estará sujeta a críticas, discrepancias y revisiones; lo contrario la convertiría en una ciencia muerta. No es extraño que muchos consideren a Senghas el cuarto Papa alemán de la orquideología, sucesor de Heinrich Gustav Reichenbach (1824-1889), Ernst Hugo Pfitzer (18461906) y Rudolf Schlechter (1872-1925).

Por último, quisiera revelar que en el Primer Congreso Internacional de Orquideología Neotropical (San José, mayo de 2003), Franco Pupulin y yo lamentamos no haber invitado al Dr. Senghas, pero nos propusimos invitarlo al segundo congreso (2007), para escuchar una conferencia suya y conferirle un reconocimiento por sus grandes aportes a la orquideología. Mas, la naturaleza dispuso algo diferente y el tiempo no fue suficiente. A menudo olvidamos que la vida de una persona es muy corta y que, por tanto, no podemos esperar indefinidamente para tomar decisiones importantes.

\section{FUENTES}

Anónimo ["Vorstand und Redaktion"]. 2004. Zum Tode von Herrn Dr. Karlheinz Senghas. Die Orchidee 55(1): 21-23.

Haber, W. 1998. Geleitwort. In: Senghas, K. (ed.). Schlechter, Die Orchideen, 3. Auflage, Band I/C. Berlin, Parey Buchverlag. S. 2057-2308.

Senger, Ingrid \& Senger, G. 2002. Geleitwort. In: Senghas, K. Bibliographie der Orchideenkunde und Rudolf Schlechter. Sonderabdruck aus Schlechter, Die Orchideen, 3. Auflage, Band I, Literatur- und Registerband. Berlin, Parey Buchverlag. S. VIIVIII.

Senger, Ingrid \& Senger, G. 2004. Zum Tode von Dr. Karlheinz Senghas. Orchideenkurier 4/04 (www.orchideen.at/Aus_OK/OK_2004_4.htm) 